\title{
The new mothers' little helpers: medicalization, victimization, and criminalization of motherhood via prescription drugs
}

\section{Michelle Smirnova \& Jennifer Gatewood Owens}

To cite this article: Michelle Smirnova \& Jennifer Gatewood Owens (2018): The new mothers' little helpers: medicalization, victimization, and criminalization of motherhood via prescription drugs, Deviant Behavior, DOI: 10.1080/01639625.2018.1449433

To link to this article: https://doi.org/10.1080/01639625.2018.1449433

曲 Published online: 13 Mar 2018.

Submit your article to this journal $₫$

Q View related articles $\llbracket$

View Crossmark data ¿ 


\title{
The new mothers' little helpers: medicalization, victimization, and criminalization of motherhood via prescription drugs
}

\author{
Michelle Smirnova and Jennifer Gatewood Owens ${ }^{b}$ \\ aDepartment of Sociology and Women's, Gender, and Sexuality Studies, Sociology and Faculty of the Women's, \\ Gender, and Sexuality Studies program, University of Missouri Kansas City, Kansas City; ${ }^{b}$ Department of Criminal \\ Justice and Criminology, Department of Criminal Justice and Criminology and Faculty of the Women's, Gender, and \\ Sexuality Studies program, University of Missouri - Kansas City, Kansas City, USA
}

\begin{abstract}
In order to understand the relationship between nonmedical prescription drug use, gender, and crime, interviews were conducted with 40 incarcerated women who self-identified as nonmedical Rx users. Of the women we interviewed, $70 \%$ were prescribed Rx drugs from their doctors to aid in recovery from cesarean section childbirth deliveries, treat postpartum depression, or for mental or physical health problems associated with childhood abuse and victimization. These women subsequently discovered that these pills also helped them cope with the stresses of caretaking and keeping the family together, particularly when experiencing intimate partner violence and prolonged poverty. Women were motivated to use $\mathrm{Rx}$ drugs in order to be a "good" mother, as defined by medical and cultural discourse; however, despite positive intentions, prolonged nonmedical use often hindered the realization of these ideals and ultimately resulted in their criminalization, incarceration, and separation from their children.
\end{abstract}

\section{ARTICLE HISTORY}

Received 28 July 2017

Accepted 23 October 2017

\section{Introduction}

The recent increase in prescription drug $(\mathrm{Rx})$ use in the U.S. coupled with the increase in nonmedical Rx use (using Rx drugs not as prescribed) has impelled the U.S. Center for Disease Control (CDC) to call Rx use a national epidemic. This "epidemic" may be most acutely experienced by women given that women's bodies (e.g., menopause) and emotions (e.g., stress) are disproportionately constructed as unhealthy and necessitating pharmaceutical intervention as compared to men (Balsamo 1996; Bartky 2003; Blum and Stracuzzi 2004; Martin 1987). Women are more likely than men to go to doctors, and are prescribed more pain medications, at higher doses, for longer periods of time (CDC 2013). They are also twice as likely as men to be prescribed a psychotropic opiate (CASA 2003) or antianxiety drug (CDC 2013). Although there is considerable research focused upon women and mothers engaged in illicit drug use and other lawbreaking behaviors (Baker and Carson 1999; Carbone-Lopez, Owens, and Miller 2012; Couvrette, Brochu, and Plourde 2016; Haritavorn 2016; Laidler 1997; McKim 2008), there is relatively little focused upon women's nonmedical Rx drug use specifically.

To better understand the experiences of women whose lives have been particularly affected by nonmedical $\mathrm{Rx}$ use, we interviewed a sample of 40 incarcerated women who self-identified as $\mathrm{Rx}$ drug users about their life experiences. These interviews revealed how identity practices tied to motherhood, as discursively defined by medicine, the law, gender, and U.S. culture were perceived to simultaneously promote and discourage the use of $\mathrm{Rx}$ drugs. This analysis draws from (Hughes

CONTACT Michelle Smirnova smirnovam@umkc.edu @ Department of Sociology, University of Missouri-Kansas City, 5100 Rockhill Road, Kansas City MO 64112.

(C) 2018 Taylor \& Francis Group, LLC 
2007) model of identity-discursive practices that conceptualizes drug use and addiction not at the individual level, but with attention to social processes, relationships, and practices. This type of analysis explores how drug use is tied to being one's self as well as being for others. "That is to say, practices of addiction are integral to the process by which addicts constitute and maintain their identity; thus, to stop engaging in these practices means, in effect, to stop being themselves" (Hughes 2007:674). As such, this research pays attention to how relationships with children, romantic partners, family, and doctors as well as discursive practices constructing motherhood, womanhood, and the family shape how women make decisions about and interpret their nonmedical Rx drug use.

We find that the women in our sample were motivated to use Rx drugs in order to be a "good" mother, as defined by medical, social, and cultural discourse, but also as a means of coping with intimate partner violence, poverty, challenges associated with single motherhood, as well as the lasting impacts of childhood trauma. Despite positive intentions, prolonged nonmedical use often hindered the realization of these ideals and ultimately resulted in their criminalization, incarceration, and separation from children. This research builds upon previous scholarship by elucidating the complex negotiations women make in their lives as they strive to manage gendered expectations of their emotions, bodies, and behaviors, particularly among criminalized or drug-using women who have been discredited by broader society (Baker and Carson 1999; Couvrette, Brochu, and Plourde 2016; Ferraro 2006; Haritavorn 2016; McKim 2008; Richie 1996). Below, we outline the discursive and institutional factors that shape these women's experiences with Rx drugs.

\section{Background}

\section{Medicalization and biomedicalization of women}

Medicalization is the process by which nonmedical physical, social, emotional, economic, or political problems become defined and treated as medical problems, usually as illnesses or disorders (Conrad 1992; Conrad and Schneider 1980). Biomedicalization takes this process a step further, transitioning the focus from existing illness, treatment, and cures to health, preventative care, enhancement, and persistent personal responsibility (Balsamo 1996; Clarke et al. 2003; Rose 2009). Instead of a "cure," the goal is "normalization" or the realization of an ideal self who is free of the risk of illness (Foucault 1979). Pharmaceuticals, particularly psych-pharmaceuticals, offer a solution to such constructed problems, insisting that $\mathrm{Rx}$ drugs make consumers a better or enhanced version of themselves (Rose 2009). This reflects changing forms of governance that measure deviance and the pathological as numeric deviations from the normal curve, and in doing so create new techno-social identities around Rx drugs (Williams, Martin, and Gabe 2011).

The medicalization and biomedicalization of women's experiences such as menstruation, premenstrual syndrome, pregnancy, childbirth, fertility, infertility, and menopause involve diagnostic labels that offer, if not impose, biomedical or surgical interventions to "treat" or "cure" these "conditions" (Almeling 2015; Clarke et al. 2003). Historically, women's life experiences have been more frequently medicalized than those of men (Balsamo 1996; Blum and Stracuzzi 2004; Mamo 2007). For example, between the 1950s and 1970s, psychopharmacological medications like Diazepam (Valium), often referred to as "Mother's Little Helpers," were commonly prescribed to women increase stamina, help with dieting, and assist in dealing with the stresses of womanhood and motherhood (Metzl 2003). This phenomenon reflected both the disproportionate medicalization of women's experiences as well as the lasting impact of compulsory motherhood (Hays 1996). Today, Rx drugs continue to be used to inscribe and manage femininity through scripts of "good" mothering and "healthy" levels of emotionality by promoting a chemical rather that social treatment for postpartum depression, anxiety, stress, and body maintenance (Bartky 2003; Blum and Stracuzzi 2004; Fox and Neiterman 2015; McKim 2008).

Childbirth is a clear example of medicalization in that it has moved over time from the social realm of the home and the midwife to the medical realm of the hospital and the obstetrician (Epstein and Lake 
2008; Mamo 2007). Today, pregnancy and birth are considered medical events. In the U.S. in 2013, nearly $99 \%$ of all births occur in hospitals and a third of these births involved a surgical cesarean section, more than double the rate that the World Health Organization (WHO) recommends (Martin et al. 2015). The cesarean section is a major surgery that requires pain medication for the patient. While some argue that this increase is the result of women's demands, research indicates the reverse: women often felt pressured by their providers and not vice versa (Declercq et al. 2013). As a result, women are prescribed Rx drugs both during delivery and for the recovery following this major surgery.

In the postpartum period, women are told that they must engage in self-sacrificing full-time infant care and breastfeeding to manage future developmental risks (Kukla 2005). Motherhood serves as an important site for disciplinary action that equates the "good mother" with particular gendered traits such as supportiveness, docility, and emotional stability that are promoted through biomedical interventions, such as Rx drugs (Bartky 2003; Mamo 2007; Martin 2003). This good mothering ideology originates from a patriarchal, heteronormative, married, White, middle-class standard derived from the experiences of mothers who "enjoy a relative greater degree of economic security and racial privilege," but is applied to all women regardless of race or ethnicity, sexual orientation, or class (Baker and Carson 1999:348). Women with less economic, social, or cultural capital are still impacted by these medical and social discourses; however, as single mothers who are under- or unemployed, insured or supported, the attempts to ascribe to such ideals prove much more difficult, particularly when dealing with challenges related to physical, emotional, sexual, and substance abuse.

\section{Victimization and mothering}

Victimization, particularly childhood abuse and intimate partner violence, is often described as a contributor to women's pathways into and continued use of drugs (Carbone-Lopez, Owens, and Miller 2012) blurring the boundaries between victim and offender, good and evil (Ferraro 2006). Women experience higher rates of childhood abuse and intimate partner violence than men (Dube et al. 2003; Kumpfer, Smith, and Summerhays 2008; Laidler 1997), in addition to greater pressures to care for others and maintain "emotional stability" (Blum and Stracuzzi 2004; McKim 2008; Shields 2007). Prescription drugs, with or without the guidance of the doctor, can offer medicalized stability following emotional and physical trauma and may help explain why women are more likely than men to be prescribed potentially addictive prescription drugs, as well as why women may continue to use these drugs without doctor supervision (CASA 2003; CDC 2013).

Even though participation in illicit drug use and crime is seen as conflicting with hegemonic images of womanhood, many victimized women engage in drug use as a response to violence or threat of violence, often from their male partners (Richie 1996). For others, "efforts to construct meaning and love as adults sometimes reproduced the pain of their childhoods" as they often confront "the same problems that their parents struggled to overcome: loneliness, overwork, bad relationships, poverty, addictions, illness and death of loved ones" (Ferraro 2006:113). As girls, these women often are saddled with family caretaking roles at an early age. In response, many seek support and acceptance outside of the family, developing romantic relationships becoming mothers early on as a means of escape from trauma or stress. The early adoption of adult roles through family caretaking or early motherhood has been directly linked with illicit drug use as a means of coping with these hardships (Carbone-Lopez and Miller 2012). The social reproduction of poverty and associated challenges of victimization means that some women and girls may use drugs as a means of "escape or fantasy" or as a means of "numbing" the pain in order to focus on school, work, and other caretaking responsibilities, including motherhood (Ferraro 2006). 


\section{Women, drugs, and prison}

In contrast to the increasing encouragement of licit drug use of pharmaceuticals by doctors, the use of illicit drugs has been constructed as antithetical to good mothering, by both medicine and the law (Smart 1996). This began in the 1980s when "the social construction of the 'welfare queen' and the so-called 'crack baby' functioned to legitimate the downsizing and de-funding of services for poor women and their children in the inner cities, who were also disproportionately women and children of color" (Murphy and Sales 2001:76-77). During this same period, tobacco-smoking pregnant women were not forced to go into treatment, jailed, or had their children taken away like women who smoked crack (Murphy and Sales 2001). The social construction of illicit substance-using mothers as "bad" resulted in the "criminalization of pregnancy" that caused the disproportionate arrest and incarceration of poor and non-White women (Baker and Carson 1999:349). As a result, many women who use drugs during and after pregnancy experience violence, stigma, and discrimination in both the public (health services), and the private (family) spheres, and in some instances, "the state uses its power to control or punish the women's behaviour by threatening to remove their children unless they enter treatment programmes" (Haritavorn 2016).

Research during this time period characterized women's relationship with illicit drug use as defined by "pathology and powerlessness" where drug-using women were either portrayed as victims or villains (Anderson 2008:1; Ferraro 2006). This severe oversimplification of the dynamic enactment of motherhood fails to pay adequate attention to the perspectives of mothers. While drug use has severe consequences for both mothers and their children (see Nair et al. 2003), some mothers argue that drugs' effects can actually assist them fulfill many of the responsibilities of motherhood and womanhood such as having energy to play with their children, be patient, or to lose weight (Brecht et al. 2004). Baker and Carson (1999) found that substance-abusing women believe they were overall good mothers who could fulfill their children's practical needs and protect them from harm. It was only when they were unable to shield their children from exposure to negative aspects of drug use or addiction that these mothers felt they had temporarily let their children down.

The increased prescription and use of Rx drugs and the punitive policies associated with the war on drugs has resulted in the growth of the female criminal justice population. Women are more likely than men to be sentenced for drug related offenses $(32.5 \%$ of women and $23.9 \%$ of men in 2011) (Ann and Golinelli 2013), which has caused some to call the "war on drugs" a "war on women" (Anderson 2008; Bush-Baskette 1998; Chesney-Lind and Pasko 1997). Despite the fact that this group may be at an elevated risk for nonmedical $\mathrm{Rx}$ use, studies frequently fail to sample from institutionalized populations (e.g., The National Survey on Drug Use and Health (Substance Abuse and Mental Health Services Administration (SAMHSA) 2010)), a particularly grave absence given these current social trends.

In exploring these pressures from their perspectives, this research foregrounds the perspectives and experiences of a population that is multiply marginalized and often written about without consultation. Our study advances previous work about drug-using women's perceptions of mothering (e.g., Baker and Carson 1999) by centering the perspective of incarcerated women who selfidentified as nonmedical Rx drug users. In doing so, we found that women sought to emulate scripts of idealized motherhood, as defined by medical, legal, and cultural institutions.

\section{Methods}

This paper draws upon 40 hour-long interviews conducted with women currently serving time in one of two Missouri women's correctional centers for a variety of charges (e.g., illicit drugs, theft, forgery, or homicide) who indicated that they used nonmedical $\mathrm{Rx}$ drugs without a prescription prior to incarceration. The interviews are part of a broader study was approved by the Institutional Review Board (\#14-337) and received a Certificate of Confidentiality from the US National Institute of Drug Abuse (\#DA-15-017) that protects respondents' survey and interview responses. As of 2016, 
Missouri remained the only state without a prescription drug-monitoring program, making it ideal for understanding nonmedical $\mathrm{Rx}$ drug use.

To recruit our sample, we sent out 240 surveys to a random sample of inmates at one of two women's prisons in Missouri. Of the 240 women who received surveys, 168 responded, yielding a $70 \%$ response rate. The survey asked detailed questions about frequency, conceptualization, and variety of $\mathrm{Rx}$ drug use, as well as detailed questions pertaining to how and when they began using and what are some of the ways they go about obtaining these drugs. The women who provided their name and ID number were then eligible for the second part of the study: the qualitative interviews with nonmedical $\mathrm{Rx}$ drug users. It is this second portion that is the focus of this article since discussions of motherhood and medicalization were only addressed in the interviews and not in the surveys.

The 40 women asked to participate in the interviews were purposively sampled from a survey based upon frequency and variety of Rx drug use, actuation behaviors, and those who had been the most "entrenched" in the Rx drug scene (by virtue of dealing Rx drugs or participating in multiple avenues of actuation) prior to incarceration because we believed they would have the most to say on the subject. Each participant was provided with a detailed written description of the study, time to ask questions, and the opportunity to consent or decline participation. Interviews were conducted in private staff offices with closed doors so that only the PIs were able to hear their responses. Only 2 of 42 women asked to participate refused. We informed all participants that their responses would be kept in confidence. In all of our research, we use pseudonyms, and all identifiable information has been omitted. After completing the interviews, a \$20 incentive was deposited into their prison accounts, an appropriate amount according to prison officials.

Demographic information of the interview participants is included in Table 1. Of note is the racial composition of our sample; $85.7 \%$ of the women in the survey identified as White and over $90 \%$ did so in the interviews. The racial composition of the women's prison was approximately $82 \%$ White; therefore, our sample is fairly representative of that population. ${ }^{1}$ Men and women of color tend to respond less frequently to survey research, given low levels of trust in the government and other official institutions, which may have contributed to the slightly lower proportion (Ebony et al. 2003; Schnittker 2004). Finally, previous research indicates that Rx drug use may be more common among Whites, hence our slightly higher proportion of White interviewees (e.g., Broman, Miller, and Jackson 2015).

Table 1. Demographic information for interview samples $(n=40)$.

\begin{tabular}{lcclrr}
\hline Age & \multicolumn{5}{c}{ Family status } \\
\hline $18-25$ & 4 & $10.0 \%$ & Mother with partner & 14 & $35 \%$ \\
$26-35$ & 20 & $50.0 \%$ & Single mother & 20 & $50 \%$ \\
$36-45$ & 13 & $32.5 \%$ & Partner, no children & 1 & $2.5 \%$ \\
$46-55$ & 3 & $7.5 \%$ & No partner, no children & 5 & $12.5 \%$ \\
$56+$ & 0 & $0.0 \%$ & & \\
Race & & & Primary Offense Incarcerated For & 15 \\
White & 37 & $92.5 \%$ & Drug offenses & $37.5 \%$ \\
Black/African American & 3 & $7.5 \%$ & Violent crime (not homicide) & 6 & $15.0 \%$ \\
& & & Property crime & 6 & $15.0 \%$ \\
Education & & & DUl & 4 & $10.0 \%$ \\
Less than high school & 13 & $32.5 \%$ & Murder/manslaughter & 4 & $10.0 \%$ \\
High school/GED & 10 & $25.0 \%$ & Other & 2 & $5.0 \%$ \\
Some college & 3 & $7.5 \%$ & & 3 & $7.5 \%$ \\
College degree & & & & \\
\hline
\end{tabular}

\footnotetext{
${ }^{1}$ We were unable to find data on race by gender in the annual reports published by the Missouri Department of Corrections. We contacted the prison where data collection took place to get a record of the number and racial distribution. Although these fluctuate on a daily basis, we were informed that there were 1250 White, 245 Black, and 28 "Other" women under supervision during the time of our interviews.
} 
Each semi-structured interview lasted approximately 45 minutes and was recorded, transcribed verbatim, and analyzed in NVivo qualitative coding software in order to identify and categorize patterns that emerged in the narratives (Corbin and Strauss 2008). In using an iterative, grounded theory approach, the authors were able to identify and code patterns across narrative responses, identify logical contradictions that required greater analysis, and disentangle the various motivations and conceptualizations of different types of $\mathrm{Rx}$ use. This technique requires constant comparisons across codes and interviews in order to identify and code for emerging patterns. The authors both coded all interviews and compared their coding schemes to verify intercoder reliability.

There are several limitations to the study. First, while their personal accounts are vitally important, they may not always line up with "objective" timelines such as how they first obtained drugs, actually used them, and so on. This is a common limitation of retrospective, qualitative research. Second, our status as women, professors, and authority figures necessarily shaped how these women talked about nonmedical Rx drug use. For example, they may have expressed more remorse or regret about their Rx drug use reflecting adherence to carefully coached scripts that are taught in rehabilitation centers and prison (McKim 2008). We were attentive to these responsive moves, both during the interviews by making it clear that we were neither medical doctors nor affiliated with the correctional facility in any way, as well as during the analysis when we recognized that certain vocabulary and interpretive strategies may reflect the broader cultural environment (e.g., regret about Rx use). We note these reflexive moves throughout our findings; however, there are likely influences that we overlooked. As such, the findings should be read an interpretive practice based upon a series of conversations with women who are often not only excluded from participating in the interpretation of these trends, but also from data on nonmedical $\mathrm{Rx}$ drug use entirely.

\section{Findings}

Of the women we interviewed, $85 \%$ were mothers and all but one of the mothers had multiple children. This is similar to national-level data, which indicates that $75 \%$ of incarcerated women were the primary caregivers of at least one child prior to incarceration (Margolies and Kraft-Stolar 2006). Scripts of idealized motherhood, as defined by medical, legal, and cultural institutions, were used to interpret and make sense of the drug use for many women in our sample. For some, nonmedical Rx drug use was perceived to facilitate the realization of such ideals, whereas others found that using $\mathrm{Rx}$ drugs hindered their ability to be effective mothers, either as the result of the drugs themselves or the risks and crimes they felt were necessary to continue their $\mathrm{Rx}$ drug use. Most women described a combination of the two: how they initially began using $\mathrm{Rx}$ drugs to be better mothers (as defined by dominant cultural scripts), but how prolonged use resulted in the opposite. Below we delineate how women often began using $\mathrm{Rx}$ drugs in obedience to doctor's orders, but then how they continued to use these drugs in attempt to realize dominant cultural scripts of good mothering associated with "doing it all" and keeping the family together. Women argued that Rx drug use was a means of coping with or escape from stress and trauma, and how prolonged Rx drug use often resulted in their criminalization and incarceration, separating them from their children and families.

\section{The new mother's little helpers: the medicalization of motherhood}

While we did not specifically ask women if they had been prescribed drugs to assist in recovery from childbirth, 35\% of our interviewees mentioned receiving pain pills for a cesarean section, and that this prescription contributed to subsequent nonmedical use of $\mathrm{Rx}$ drugs. For example, Ingrid, explains that, "I didn't really start having a problem with [Rx drugs] until my-I had my son. They did a C-section and they gave me a ton of those pain pills. I was using them to get through taking care of a baby and all that." We might surmise from this unsolicited finding that other women may have also been prescribed $\mathrm{Rx}$ drugs for a delivery, but potentially did not mention it. The prescription of drugs for childbirth proved to have lasting effects for a number of these women. One 
respondent, Katie, a White 27-year-old woman with high school degree, moved out of the house at 15 after she became pregnant and her parents were going through a divorce. She describes how,

After I had my child, I had a C-section; they gave me prescription Percocet, that was it, for five years, I was straight addicted to opiates, bad. Wasn't getting up, wasn't cooking dinner, you know, my paychecks go to it, not going to work unless I have it. That at first was just, you know, oral, and then we started shooting up dilaudids and stuff.

Seventy percent $(28 / 40)$ of the women described at least one drug that was initially prescribed to them by a doctor before taking it in greater quantities, intravenously, and/or obtaining it from a source other than a doctor.

Women often explained that they used Rx drugs because a doctor had prescribed them and therefore Rx drugs felt more "healthy" or "respectable" than illicit drugs. As Lyndsey argues, "my doctor gave [Rx drugs] to me, therefore it can't be that bad..." Although Gina was not sure whether she believed that Rx drugs were less potent than illicit drugs, she explains that using Rx drugs "felt different, though. It was more acceptable I think. I wasn't on the street getting it. I was getting it from a reputable doctor with my name on the prescription even though I was lying to get it I felt like I'm better than [other drug users]." Likewise, Betsy was insistent that all of her Rx drugs had been prescribed and when compared to street drugs, she remarked, "it's just different." Rhianna expresses how pills are more common and acceptable stating, "when you think of pills, everybody uses pills, doctors prescribe you pills. It's got a better reputation. Everybody uses pills." Even more extreme, when asked if her mother knew about her Rx drug use, Ikeisha says, "Yeah, my mom did. She always knew... She looks at it differently because like I said, she's a nurse, so in her mind it's not illegal drugs, so that was the one thing I could do around my mom that she would support because at least I wasn't going out and getting high on weed, or on meth."

Women in our sample perceived that Rx drug users were of a higher social class than illicit drug users. For example, Kelly explains that Rx drug users are more typically "women, as odd as that may sound and it's more middle class or upper class." This feeling of Rx drugs as being more middle or upper class does not reflect the class conditions of the women Rx drug users we spoke to, but does reflect a differing subjective interpretation of this drug use as White, middle class, and emulating respectable femininity. For example, even when desperate enough to dig through the trash for pain pill patches, Ingrid thought no one knew about her use "[b]ecause we were still going to church, the kids were in a Christian school. We were at the Parent Teacher Group at the Christian school. We were trying to do the right thing and I felt like a hypocrite because underneath it all I had this addiction that I can't kick.” Rx drugs helped Ingrid maintain an outward image of good mothering, though her addiction ultimately caused her to lose her kids and her family. Tanisha offered a similar perspective, "I honestly thought, 'Nobody knows that I'm taking what I'm taking, I'm a good mom, I'm a good wife. I can do anything I want. Nobody is gonna know." Because they were using Rx drugs as opposed to illicit drugs, drugs that were often initially prescribed by doctors in settings populated by middle- and upper-class people, many women felt as though their use was more seamless with their performance of idealized motherhood.

\section{To escape or do it all? the effects of victimization on mothering}

The women in our sample disproportionately grew up in households and neighborhoods where violence, poverty, and incarceration were much more prevalent than the general population. Of the women we asked directly, $48 \%$ grew up with an incarcerated family member (10/21), 55\% with drug use (22/40), 48\% experienced mental health issues (19/40), and $45 \%$ received government public assistance $(10 / 22){ }^{2}$ Further, three quarters of the women $(30 / 40)$ we interviewed had been abused as

\footnotetext{
${ }^{2}$ Some questions were introduced halfway through the protocol and therefore not asked of earlier respondents, hence the variations in sample size.
} 
children or in romantic relationships, a finding that parallels other samples of incarcerated women and sexual abuse or intimate partner abuse (e.g., Browne, Miller, and Maguin 1999).

Ferraro (2006) identifies "dissociation" and "escape," as well as "caretaking and perfectionist behavior, [such as] achieving success in school and work" as strategies for coping with childhood victimization (51). The women in our sample reflected these patterns by describing how they used Rx drugs to "numb" themselves from childhood abuse, but also to assist in the realization of idealized (middle-class) prototype of motherhood. For example, Yolanda used Rx drugs "to escape from reality and stuff. I have had some things happen in my past. When I was 13 my step dad raped me. For 6 months after that my mom was with him. So I had some issues." Nancy has also "been through a lot of emotional trauma. That was always my scapegoat. It made the world better. To me that was self-medication." Both Sara and Stacy describe Rx drug us as a "coping mechanism."

Other women described using Rx drugs to "do it all," a white, middle-class feminist mantra that describes the ability to provide support and stability for their families at home and at work through intensive mothering (Milkie and Warner 2014). However, they expressed feeling overwhelmed and overburdened in juggling these multiple roles as mothers, caretakers, and often breadwinners for the family. Women often perceived that Rx drugs helped them fulfill these competing responsibilities. For example, Ingrid, a White, 39-year-old high school educated woman, describes receiving opiates for "my second child that I had, I had a C-section and they gave me Vicodin for that, or you know Lorcet and stuff." After the birth, she was tired and in pain,

So, I was like, 'This'll probably give me some energy', because I was really tired from moving stuff all day. So, I took one and I threw up and then I had this immediate head rush and it got me through the rest of the day and that night moving back and forth, loading the car, taking care of everything.

Katie similarly describes how opiates gave her the energy to manage her responsibilities as a mother; "especially just after having a baby, you know, it takes away that baby blues and gives you energy and you know, you're just high." Lauren had a C-section that "they screwed up pretty bad" in additional several other surgeries. The Rx drugs "helped after the surgeries to be able to get around, but I would just say, I felt like super mom when I was on them because I could get everything done that I needed to, and not have the postpartum blues about not doing this or that. It just made me forget about problems."

Rhianna offers a narrative that initially sounds the same as that of Ingrid, Katie, and Lauren, but then admits in the same breath that they transformed her into an "abusive mom." She explains how the Rx drugs "would get you going, it would get you going. I was wonder woman. Especially after having kids, I would trade my food stamps for Adderall. I think it helped me keep my house clean and keep my cool. The food we did have, I didn't have to eat as much of." She admits that "I had the energy to deal with my kids but at the same rate, I came down I was mean, and I was an abusive mom [...] cursing people out, throwing stuff. I threw a lot of things. I broke things." Similar to other research with victimized and criminalized women, Rhianna learned early on how to submerge her own needs to the needs of her family (Ferraro 2006; Raphael 2000; Richie 1996). While Rx drugs helped her enact the qualities of a good mother by giving her energy and emotional stability, they ultimately hindered her ability to be a good mother as she was unable to financially or emotionally support her children. Rhianna, like $70 \%$ of our sample, was initially prescribed Rx drugs through a doctor. In her case, she was placed on antidepressants at the age of 13 and treated for "postpartum depression after my second child."

The pressure to be perfect to overcompensate for their imperfect childhoods was also often evident in these women's concerns about their weight. As Dworkin and Wach (2004) argue, poor women must often sustain a first shift (paid labor), a second shift (child care and household responsibilities), in addition to a third shift: dieting or fitness regimens to stay attractive or "healthy." In our sample, several women described how they wanted to lose weight in general or immediately following childbirth. Helen, for example, was transitioning off of meth and using Adderall to help her avoid withdrawal systems, work two jobs, and lose the weight she gained from childbirth. She 
believes that Adderall helped curb her craving for methamphetamines; she argues the pills "keep me up during the day and to help me lose weight so I wouldn't have to eat as much." Francis explains that she has always been "obsessed with [her] weight" and "used to be able to buy Phentermine off the internet, and we used it to lose weight [...] They were really cheap, ... [and they] pick you up, like go faster. [...] You got real skinny." As mothers who may also be seeking romantic partners, these women experience competing pressures to be emotionally, physically, and financially responsible, as well as physically attractive for current or potential partners.

\section{Keeping the family together, until it falls apart: drugs, crime, and prison}

Mothering at the margins involves extensive efforts and many women described how $\mathrm{Rx}$ drugs helped them fulfill key obligations to dependents by helping them "cope" or "hold [themselves] together" as well as "keeping the family together." The identity of being a "good mother" was a central theme that appeared in all of our interviews with mothers, as well as with two others who wished that they had become mothers. Of the 34 women who had children in our interview sample, 26 (or 76\%) were single mothers at some point while raising their children, making daily responsibilities even more burdensome and the pressures to "do it all" more persistent. Although Ingrid's adoptive father molested her as a child, she says, "I'm glad that he didn't go to jail because it would have really torn my mom up and done even more damage to our family." This desire to "keep the family together" began at a very young age, before she herself was a mother, reflecting the current family demographics of the most disadvantaged in America who are disproportionately impacted by mass incarceration (Edin and Kefalas 2005).

Potentially as a result of their own fractured childhoods as well as pressures associated with compulsory motherhood, many women in our sample prioritized keeping the family together at any cost. For example, Tanisha, a 49-year-old White high school educated woman, explains how she used Rx drugs to manage a difficult relationship and keep the family together, but the result was the exact opposite:

I went through a period of like five years with my ex-fiancé, where he beat me up all the time. I'd take pain meds just to dull the pain, and deal with getting beat up on a daily basis. [...] I felt like I couldn't walk away. My two oldest kids were with him, I thought, 'Well we have kids, things will be better, I'm not gonna walk away.' My parents were divorced when I was two; I didn't want to be like that with my kids. I just thought, 'I'll stay, I'll stay I'll stay,' and ended up almost dead from it, losing custody of my two oldest kids because of it and going to prison.

Similar to Ferraro's (2006) research, many mothers in our sample were forced to choose between "staying in abusive relationships, leaving children home alone while they work, committing minor property or drug crimes, relinquishing custody, or moving into overcrowded and temporary shelters" (122). These women faced incredible obstacles as they seek to address physical, financial, and emotional needs of their children. Although the initial intent of Rx drug use was to maintain and enhance relationships, with prolonged use "women become increasingly isolated from otherstheir children, partners, friends, and families" just as women become on other drugs, such as methamphetamines (Laidler 1997:132). Understood in the context of their strained relationships with family and children, women continue to use Rx drugs to mitigate associated emotional and physical symptoms of isolation, but as a result distance and ultimately sever these very ties.

Many women realized that their $\mathrm{Rx}$ drug use was a problem through their children. This was particularly painful, given that many have perceived that the $\mathrm{Rx}$ drugs were helping them be better mothers. For example, Gina recounts how difficult it was to hear from her daughter that on Rx drugs " you were sickening. You were so sickening. I could tell you were lying to me and it was just sickening to see it." Tanisha says it was "like a dagger to the heart" when her daughter told her, "I feel like you chose the drugs over me. You were more worried about getting it and running around in the emergency rooms and doctors and all that stuff, than you were with anything going on with 
us. It felt like you just pushed us away and chose that over us.” This perception was the farthest from the truth, as most women discussed how being there for their children was the most important of all. For example, to avoid sleeping, Helen, a 30 -year-old White woman with a high school education, described using drugs to help her spend more time with her kids. "I was working overnight shift. I had to take care of my kid during the day." Although Rx use initially helped her stay awake and be present in her children's lives, eventually the craving for more $\mathrm{Rx}$ drugs interfered with these very mothering aspirations. This finding parallels that of Richie's (1996), who found that women were motivated to protect their children and maintain a nuclear family, but that these desires were compromised by a constant lack of financial and emotional resources, which compelled them to commit crimes.

While a number of women described how they sought out $\mathrm{Rx}$ drugs to help them cope with emotional stress, upon reflection, many cited how Rx drugs numbed them, making it difficult to be there for their children in the capacity that they intended. For example, Dee-Ann said she would be "zombied out" on pills, which "affected me, my children, my spouse. I don't want to do anything because I was lost in the world of prescription drugs." Penny similarly explained that, "I thought I was a good mom, yet I'm at football practices sick as a dog, because I can't have pills, or ready to leave because I had more ... My kids see me passed out in the bathtub. But I was there, right?" Janice's describes how "my 11 year old hated me on Xanax. My oldest son Joey, there would be times that he would have to take care of me because I was so messed up." These narratives reflect the precocious role entry that their children endure as a result of their drug use, not unlike their own childhood experiences with their drug using or negligent parents (Carbone-Lopez and Miller 2012). These narratives also foreshadow these women's criminalization and incarceration. In the end, these women lost the ability to be with their children at all and they had to navigate the complexity of their present circumstances.

\section{Discussion and conclusions}

Previous research with incarcerated women has similarly demonstrated the tremendous meaning of motherhood (Couvrette, Brochu, and Plourde 2016; Enos 2001; Ferraro 2006; Haney 2010; Raphael 2000; Richie 1996). As such, many of their actions are interpreted as sustaining or harming this primary salient identity. Some women believed that drug use and other lawbreaking behaviors assisted with the enactment of an idealized motherhood by improving their levels of patience and energy or helping them cope with daily struggles, work, and family relationships. Other women, upon post hoc reflection, believed that their drug use either created a false sense of control or that their cravings caused them to prioritize drugs and associated crimes over their children and families. As a result, despite the positive intentions and initial positive effects, with prolonged use, women found that nonmedical Rx use often hindered rather than supported the good mothering script.

Living under considerable physical, financial, psychological, and interpersonal strain, many women used Rx drugs as a way to cope with daily struggles. The language of "self-medication" fits with an individualist ideology; but in doing so hides normative pressures to ascribe to particular prototypes of behavior and emotions; women who fail to meet these standards are in need of fixing through medical intervention. Likewise, it fails to encompass women who are "forced or coerced" into drugs and crime "by their culturally expected gender roles, the violence in their intimate relationships, and their social position in the broader society" (Richie 1996:133). Drug use is not simply a recreational choice to get high, but the results of several competing social pressures that can encourage the use of drugs to meet the overwhelming demands of motherhood at the margins (Hays 1996).

Maternal drug use is constructed as irresponsible, selfish, and dangerous to children in most, if not all societies (Klee 1998); therefore, motherhood and drug use are conceptually incompatible, which can produce a serious identity strain. Our findings build upon previous research that explores the challenges and tensions experienced by drug use, criminalized women and mothers, by exploring 
the intersecting influences of medicine, law, and gender in both the promotion and punishment of nonmedical Rx drug use (Haritavorn 2016; Klee 1998; Laidler 1997). As others have found, women using drugs wrestle with ideals and realities of motherhood that are often incompatible (Baker and Carson 1999; Ferraro 2006). In our work, we found that interaction of nonmedical Rx drug use, motherhood, and crime can be understood through the motherhood-as-discursive-practice, where the importance of certain attributes, such as energy or attentiveness guide whether women view their drug use positively or negatively.

Our research challenges constructions of these women as selfish or heedless in their actions. The women in our study struggled to keep their families afloat amid constant deprivations and indignities (Comfort 2008; Haney 2010; Hays 1996). As such, what may appear illogical to the outside observer, such as staying in an abusive relationship or using Rx drugs to manage stress, depression, victimization, and pain, may in fact be a reflection of financial necessity or the desire to promote long-term family ideals such as keeping the family intact (Edin and Kefalas 2005). Their stories are complex and interwoven with specific descriptions of how they perceived they were enacting the "good" mothering script, but then with post hoc reflection, they describe how positive intentions turned afoul as the result of $\mathrm{Rx}$ drug use or associated behaviors. Further, this research draws attention to the culpability of doctors and healthcare providers, who overprescribe medications that may not be necessary or encourage unnecessary cesarean sections child deliveries that result in such prescriptions (Almeling 2015; Declercq et al. 2013; Epstein and Lake 2008; Mamo 2007; Martin et al. 2015).

Consistent with Baker and Carson (1999) was the limited role of race/ethnicity or class in their discussion of motherhood. Although women mentioned Rx drugs being "higher class" than other illicit drugs, there was little evidence the users themselves were middle class. However, this may be the result of interviewing incarcerated women who are more likely to come from poor or workingclass backgrounds (Rabuy and Kopf 2015). Given that most of our sample was White, it may also signify that racial privilege by White women is unacknowledged because it remains unseen by them (Baker and Carson 1999; Frankenberg 1993).

This study moves the discussion to include incarcerated women's experiences with nonmedical Rx use; a group frequently ignored but who may reflect the most extreme of these social and medical pressures and as a result are arguably suffering the gravest of ramifications (e.g., loss of freedom, custody of their children, etc.). The women in our sample regularly talked about using Rx drugs to assist with their duties or relationships (e.g., to help maintain energy to keep up with children) or to manage to struggle or pain associated with abusive relationships and financial stress. Each of these motivations for use reflects broader issues that disproportionately affect socioeconomically disadvantaged women; particularly for those who experienced childhood trauma related to substance abuse, physical, emotional, or sexual abuse, or the absence of parents due to death, incarceration, or other public interventions. It is important to highlight how the criminalization of drug use may in fact contribute to the intergenerational transmission of poverty, fractured families, and coping behaviors associated with these traumas. Further, this study contributes to research that demonstrates how the "processes of the activity rather than its result" reveals the influence of gender as a structuring force upon womanhood in general and motherhood in particular (Foucault 1979:136).

\section{Acknowledgment}

The authors would like to thank the women who participated in these surveys and interviews for opening up and sharing their perspectives with us and to the Missouri Department of Corrections for facilitating this research. We are also grateful for the Women's, Gender, and Sexuality Studies program at the University of Missouri-Kansas City for their generous grant to support this research. Finally, we would like to thank Emily Mann and Melissa Milkie for their insightful comments on an earlier draft of this paper, in addition to constructive feedback from the two anonymous reviewers. 


\section{Notes on contributors}

MICHELLE SMIRNOVA is an Assistant Professor of Sociology and Associate Faculty member of the Women's, Gender, and Sexuality Studies program at the University of Missouri in Kansas City. Her research expertise includes the sociology medicine, gender, intersectionality, and cultural expressions of power and resistance.

JENNIFER GATEWOOD OWENS is an Assistant Professor at the University of Missouri in Kansas City in the department of Criminal Justice and Criminology and an Associate Faculty member of the Women's, Gender, and Sexuality Studies program. Her research expertise includes victimology, survey research, gender, and substance use.

\section{References}

Almeling, Rene. 2015. "Reproduction.” Annual Review of Sociology 41:423-42.

Anderson, Tammy L. 2008. Neither Villain nor Victim: Empowerment and Agency among Women Substance Abusers. New Brunswick, NJ: Rutgers University Press.

Ann, Carson, E. and Daniela Golinelli. 2013. Prisoners in 2012. Trends in Admissions and Releases, 1991-2012. Bureau of Justice Statistics. Washington, DC: U.S. Department of Justice. Retrieved June 29, 2016 https://www.bjs.gov/ content/pub/pdf/p12tar9112.pdf.

Baker, Phyllis L. and Amy Carson. 1999. "I Take Care of My Kids: Mothering Practices of Substance-Abusing Women." Gender \& Society 13(3):347-63.

Balsamo, Anne. 1996. Technologies of the Gendered Body: Reading Cyborg Women. Durham, NC: Duke University Press.

Bartky, Sandra L. 2003. "Foucault, Femininity, and the Modernization of Patriarchal Power." Pp. 25-45 in The Politics of Women's Bodies: Sexuality, Appearance, and Behavior, edited by. R. Weitz. New York: Oxford University Press.

Blum, Linda M. and Nena F. Stracuzzi. 2004. "Gender in the Prozac Nation: Popular Discourse and Productive Femininity." Gender \& Society 18:269-86.

Brecht, Mary-Lynn, Ann O’Brien, Christina Von Mayrhauser, and M. Douglas Anglin. 2004. "Methamphetamine Use Behaviors and Gender Differences." Addictive Behaviors 29:89-106.

Broman, Clifford L., Paula K. Miller, and Emmanuel Jackson. 2015. "Race-Ethnicity and Prescription Drug Misuse: Does Self-Esteem Matter?" Child \& Adolescent Behavior 3:1-6.

Browne, Angela, Brenda Miller, and Eugene Maguin. 1999. "Prevalence and Severity of Lifetime Physical and Sexual Victimization among Incarcerated Women." International Journal of Law and Psychiatry 22(3):301-22.

Bush-Baskette, Stephanie R. 1998. “The War on Drugs as a War against Black Women.” Pp. 113-129 in Crime Control and Women: Feminist Implications of Criminal Justice Policy, edited by S. L. Miller, Thousand Oaks, CA: Sage Publications.

Carbone-Lopez, Kristin and Jody Miller. 2012. "Precocious Role Entry as a Mediating Factor in Women's Methamphetamine Use: Implications for Life-Course and Pathways Research.” Criminology 50:187-220.

Carbone-Lopez, Kristin, Jennifer Gatewood Owens, and Jody Miller. 2012. "Women's "Storylines" of Methamphetamine Initiation in the Midwest." Journal of Drug Issues 42:226-46.

Centers for Disease Control and Prevention (CDC). 2013. "Vital Signs: Overdoses of Prescription Opioid Pain Relievers and Other Drugs among Women-United States, 1999-2010.” MMWR. Morbidity and Mortality Weekly Report 62:537-42.

Chesney-Lind, Meda and Lisa Pasko. 1997. The Female Offender: Girls, Women and Crime. Thousand Oaks, CA: Sage Publications.

Clarke, Adele E., Janet K. Shim, Laura Mamo, Jennifer Ruth Fosket, and Jennifer R. Fishman. 2003. "Biomedicalization: Technoscientific Transformations of Health, Illness, and U.S. Biomedicine." American Sociological Review 68:161-94.

Comfort, Megan. 2008. Doing Time Together: Love and Family in the Shadow of the Prison. Chicago: University of Chicago Press.

Conrad, Peter. 1992. "Medicalization and Social Control." Annual Review of Sociology 18:209-32.

Conrad, Peter and Joseph W. Schneider. 1980. Deviance and Medicalization: From Badness to Sickness. St. Louis, MO: Mosby.

Corbin, Juliet and Anselm Strauss. 2008. Basics of Qualitative Research: Grounded Theory Procedures and Techniques. Thousand Oaks, CA: Sage Publications.

Couvrette, Amélie, Serge Brochu, and Chantal Plourde. 2016. “The "Deviant Good Mother" Motherhood Experiences of Substance-Using and Lawbreaking Women.” Journal of Drug Issues 46(4):292-307.

Declercq, Eugene R., Maureen P. Carol Sakala, Sandra Applebaum Corry, and Ariel Herrlich. 2013. Listening to Mothers SM III: Pregnancy and Birth. New York: Childbirth Connection.

Dube, Shanta R., Vincent J. Felitti, Daniel P. Maxia Dong, Wayne H. Giles Chapman, and Robert F. Anda. 2003. "Childhood Abuse, Neglect, and Childhood Dysfunction and the Risk of Illicit Drug Use: The Adverse Childhood Experiences Study.” Pediatrics 111:564-72. 
Dworkin, Shari L. and Faye Linda Wachs. 2004. Getting your Body Back":Postindustrial Fit Motherhood in Shape Fit Pregnancy Magazine. Gender \& Society. 18(5):610-624. doi:10.1177/0891243204266817

Ebony, Boulware, L., Lisa A. Cooper, Lloyd E. Ratner, Thomas A. LaVeist, and Neil R. Powe. 2003. "Race and Trust in the Health Care System." Public Health Reports 118:358-65.

Edin, Kathryn and Maria Kefalas. 2005. Promises I Can Keep: Why Poor Women Put Motherhood before Marriage. Berkeley: University of California Press.

Enos, Sandra. 2001. Mothering from the Inside: Parenting in a Women's Prison. Albany, NY: SUNY Press.

Epstein, Abby and Ricki Lake. 2008. The Business of Being Born. videorecording. Burbank, CA: New Line Home Entertainment.

Ferraro, Kathleen J. 2006. Neither Angels nor Demons: Women, Crime, and Victimization. Boston: Northeastern University Press.

Foucault, Michel. 1979. Discipline and Punish: The Birth of the Prison. New York: Vintage Books.

Fox, Bonnie and Elena Neiterman. 2015. "Embodied Motherhood: Women's Feelings about Their Postpartum Bodies." Gender \& Society 29:670-93.

Frankenberg, Ruth. 1993. White Women, Race Matters: The Social Construction of Whiteness. Minneapolis: University of Minnesota Press.

Haney, Lynne. 2010. Offending Women: Power, Punishment, and the Regulation of Desire. Berkeley: University of California Press.

Haritavorn, Niphattra. 2016. "I Am Just a 'Maae' (Mother): Experiences of Mothers Injecting Drugs in Thailand." Sociology of Health \& Illness 38(7):1167-79.

Hays, Sharon. 1996. The Cultural Contradictions of Motherhood. New Haven, CT: Yale University Press.

Hughes, Kahryn. 2007. "Migrating Identities: The Relational Constitution of Drug Use and Addiction." Sociology of Health \& Illness 29:673-91.

Klee, Hilary. 1998. "Drug-Using Parents: Analysing the Stereotypes.” International Journal of Drug Policy 9(6):437-48.

Kukla, Rebecca. 2005. Mass Hysteria. New York: Rowman \& Littlefield.

Kumpfer, Karol L., Paula Smith, and Julia Franklin Summerhays. 2008. “A Wakeup Call to the Prevention Field: Are Prevention Programs for Substance Use Effective for Girls?” Substance Use \& Misuse 43:978-1001.

Laidler, Karen Joe. 1997. "Going Home: Tille Double-Edged Sword: The Paradox of Family among Women Drug Users in Hawai' i." Social Process in Hawaii 38:122-37.

Mamo, Laura. 2007. Queering Reproduction: Achieving Pregnancy in the Age of Technoscience. Durham, NC: Duke University Press.

Margolies, Julie Kowitz and Tamar Kraft-Stolar. 2006. When "Free” Means Losing Your Mother: The Collision of Child Welfare and the Incarceration of Women in New York State. Correctional Association of New York.

Martin, Emily. 1987. The Woman in the Body: A Cultural Analysis of Women's Reproduction. Boston, MA: Beacon.

Martin, Joyce A., Brady E. Hamilton, J. K. Osterman Michelle, Sally C. Curtin, and T. J. Matthews. 2015. "Births: Final Data for 2013." National Vital Statistics Reports 64 (1). Hyattsville, MD: Centers for Disease Control and Prevention, National Center for Health Statistics.

Martin, Karin A. 2003. “Giving Birth like a Girl.” Gender \& Society 17:54-72.

McKim, Allison. 2008. "Getting Gut-Level” Punishment, Gender, and Therapeutic Governance." Gender \& Society 22:303-23.

Metzl, Jonathan M. 2003. “"Mother’s Little Helper”: The Crisis of Psychoanalysis and the Miltown Resolution.” Gender \& History 15:240-67.

Milkie, Melissa A. and Catharine H. Warner. 2014. "Status Safeguarding: Mothering Work as Safety Net." in Intensive Mothering: The Cultural Contradictions of Modern Motherhood, edited by. Linda Ennis. Bradford, ON: Demeter Press.

Murphy, Sheigla and Paloma Sales. 2001. "Pregnant Drug Users: Scapegoats of the Reagan/Bush and Clinton-Era Economics." Social Justice 28(4):72-95.

Nair, Prasanna, Maureen E. Schuler, Maureen M. Black, Laurie Kettinger, and Donna Harrington. 2003. "Cumulative Environmental Risk in Substance Abusing Women: Early Intervention, Parenting Stress, Child Abuse Potential, and Child Development." Child Abuse \& Neglect 27(9):993-1018.

National Center on Addiction and Substance Abuse at Columbia University (CASA). 2003. The Formative Years: Pathways to Substance Abuse among Girls and Young Women Ages 8-22. New York: CASA.

Rabuy, Bernadette and Daniel Kopf. 2015. "Prisons of Poverty: Uncovering the Pre-Incarceration Incomes of the Imprisoned." Prison Policy Initiative. Retrieved September 21, 2017 https://www.prisonpolicy.org/reports/income.html Raphael, Jody. 2000. Saving Bernice: Battered Women, Welfare, and Poverty. Boston: Northeastern University Press.

Richie, Beth. 1996. Compelled to Crime: The Gender Entrapment of Battered Black Women. New York: Routledge.

Rose, Nikolas. 2009. The Politics of Life Itself: Biomedicine, Power, and Subjectivity in the Twenty-First Century. Princeton, NJ: Princeton University Press.

Schnittker, Jason. 2004. "Social Distance in the Clinical Encounter: Interactional and Sociodemographic Foundations for Mistrust in Physicians." Social Psychology Quarterly 67:217-35.

Shields, Stephanie A. 2007. "Passionate Men, Emotional Women: Psychology Constructs Gender Difference in the Late 19th Century." History of Psychology 10:92-110. 
Smart, Carol. 1996. ““Deconstructing Motherhood.” Pp. 37-57.” in Good Enough Mothering? Feminist Perspectives on Lone Motherhood, edited by. E. B. Silva. London: Routledge.

Substance Abuse and Mental Health Services Administration (SAMHSA). 2010. Results from the 2009 National Survey on Drug Use and Health: Volume I. Summary of National Findings. Office of Applied Studies, NSDUH Series H-38A, HHS Publication No. SMA 10-4586. Rockville, MD.

Williams, Simon J., Paul Martin, and Jonathan Gabe. 2011. "The Pharmaceuticalisation of Society? A Framework for Analysis." Sociology of Health \& Illness 33:710-25. 